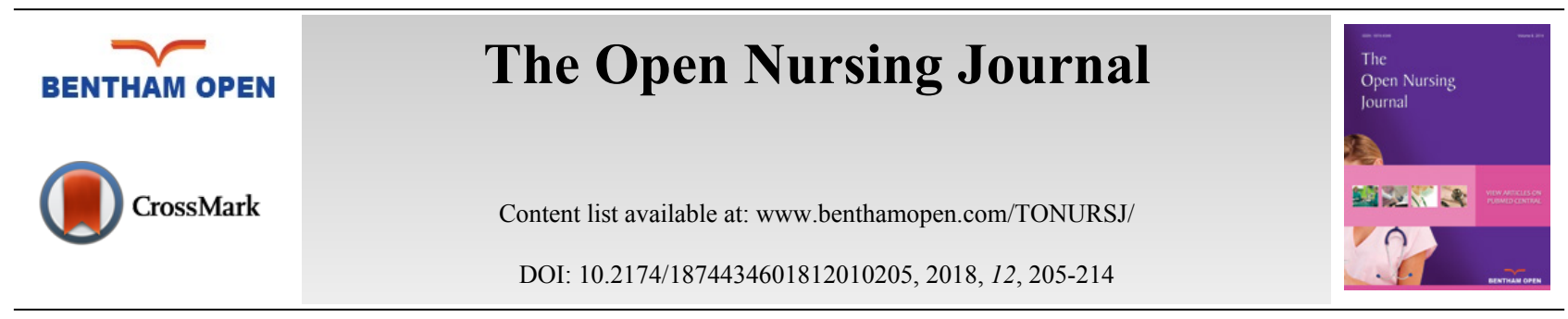

RESEARCH ARTICLE

\title{
Depressive Symptoms and Complications Early after Acute Myocardial Infarction: Gender Differences
}

\author{
Mohannad Eid AbuRuz and Ghadeer Al-Dweik \\ College of Nursing, Applied Science Private University, Amman, Jordan
}

Received: March 18, 2018

Revised: August 5, 2018

Accepted: September 10, 2018

\begin{abstract}
:
Background:

Cardiovascular disease is the first leading cause of death worldwide. Coronary heart disease is the most common manifestation of cardiovascular disease. Acute myocardial infarction is the primary manifestation of coronary heart disease. Depression is a common and predicted complication after acute myocardial infarction. Limited studies evaluated gender differences in depressive symptoms after acute myocardial infarction especially in developing countries.
\end{abstract}

\section{Objective:}

The study aimed to determine whether there was a difference in depression levels and rate of complications based on gender early after acute myocardial infarction.

\section{Method:}

This was a prospective comparative study on 230 patients ( 150 men and 80 women) with a confirmed diagnosis of acute myocardial infarction. All participants signed an informed consent, filled sociodemographic and clinical questionnaire and the Depression Subscale of the Hospital Anxiety and Depression Scale. Clinical data were abstracted from the participants' medical record after discharge.

\section{Results:}

Eighty-six participants (37.4\%), 54 men and 32 women, developed 1 or more complications during hospitalization. Female patients were more depressed $(14.4 \pm 3.5 v s .8 .3 \pm 2.6)$ and developed more complications $(1.9 \pm 0.9 v s .0 .8 \pm 0.5)$ than male patients did. Depressive symptoms increased the occurrence of complication by $40 \%$ and $33 \%$ for female and male patients respectively after controlling for sociodemographic and clinical variables.

\section{Conclusion:}

Depressive symptoms independently predicted complications after acute myocardial infarction in both men and women. The inclusion of depression assessment tools in acute myocardial infarction treatment protocols is highly recommended.

Keywords: Depressive symptoms, Acute myocardial infarction, Complication, Developing countries, Coronary Heart Disease (CHD), CVD.

\section{INTRODUCTION}

Cardiovascular Disease (CVD) is the first leading cause of death in many countries [1, 2]. The most common manifestation of CVD is the Coronary Heart Disease (CHD) [3]. The prevalence of CHD in US was approximately 16 million [1]. It affected approximately 6.6 million US women annually and remained the leading cause of morbidity and

\footnotetext{
* Address correspondence to this author at the College of Nursing, Applied Science Private University, Amman, Jordan, Tel: 00962790262408, Fax: 0096265232899; E-mails: mohannadeid@yahoo.com; m_aburuz@asu.edu.jo
} 
mortality threat in women. Of these, 2.7 million had a history of acute myocardial infarction (AMI) among which $>53,000$ died of this AMI, and an estimated 262,000 women were hospitalized for an acute coronary syndrome (AMI and unstable angina) [1].

In Europe, about $55 \%$ of all female deaths are caused by CVD, especially CHD, compared with $44 \%$ of all male deaths [4]. The mortality of CHD will increase by $174 \%$ in men and 146\% in women in the Middle East countries [5]. In Jordan, a Middle Eastern developing country, according to the latest WHO report, CHD deaths reached nearly $19 \%$ of total deaths. The death rate per 100,000 due to CHD is 131 of population, ending to make Jordan to be ranked number 46 in the world [2].

Acute myocardial infarction is the primary manifestation of CHD. Depression is associated with negative short and long-term outcomes among patients with AMI [6,7]. Depression is common and persistent in AMI survivors [7, 8]. Growing evidence supports that post-AMI depression is an independent risk factor for future cardiac events and mortality [6, 7, 9 - 12]. Furthermore, it has been shown that depression predicted complications after AMI [7, 9, 13 15]. Most of these complications occur during the early phases of the event and might begin as early as the first 20 minutes [16 - 19].

In previous studies, different complications have been reported in patients who developed AMI including arrhythmias (i.e. ventricular tachycardia, ventricular fibrillation), inflammation (early pericarditis and post-AMI syndrome), as well as left ventricular mural thrombus. In addition, acute recurrent ischemia, re-infarction, cardiogenic shock, and in-hospital death were also reported [7, 15 - 19].

Depression is a prevalent phenomenon across the world [20 - 22]. With few exceptions, females have a higher incidence and level of depressive symptoms compared to males [10, 20 - 25]. For instance, in a meta-analysis of 16 prospective studies about sex differences in depression post AMI, 14 studies with 7202 participants out of 10175 reported that females had higher levels of depressive symptoms compared to males [20]. Usually, the rate of depressive symptoms is higher post AMI compared to the general population [7, 20].

Depression is the most common mental illness in females who have twice the risk of major depressive disorder as compared with males [26 - 29]. Population studies from Canada [30], Germany [31], and Switzerland [32] all reported that females are at least twice as likely as males to suffer from major depressive disorder. A prospective study conducted in US to examine the extent to which depressive symptoms accounted for the higher rates of post-AMI adverse outcomes in women concluded that women have a higher prevalence of depressive symptoms after AMI compared with men [33]. Data from large epidemiological studies revealed that males and females often report distinct differences in the self-reported somatic depressive symptoms of depression [34, 35]. Somatic depressive symptoms include sleep disturbance, appetite disturbance, and fatigue for at least two weeks [34, 35].

In a scientific statement from the American Heart Association about depression as a risk factor for poor prognosis among patients with acute coronary syndrome, 24 out of 53 studies included AMI patients [36]. Nearly all these 24 studies used self-reported questionnaires to assess depression. Among these 24 studies; 21 studies found an association between depression and all-cause mortality. The remaining three studies did not find a significant association [36]. Moreover, in this statement 11 studies checked the effect of depression on cardiac mortality after AMI. Among these studies; 8 studies reported a significant relationship between depression and cardiac mortality. However, the remaining three studies did not report any significant relationship [36]. Based on that the American Heart Association supported the evaluation of depression as a risk factor for complications and mortality after acute coronary syndrome [36].

Unfortunately, in developing countries, medical research has historically neglected the health needs of women, apart from reproductive concerns. Multiple studies have shown that women with acute coronary syndromes are less likely to be treated with guideline-directed medical therapies [37, 38]. Improving AMI morbidity and mortality and closing the knowledge gaps on AMI clinical presentations considering the gender differences and treatments for women are public health priorities. Limited studies have specifically evaluated gender differences in specific depressive symptoms reported after AMI event especially in developing countries. There is a lack of research regarding gender differences among Jordanian patients with AMI. Therefore, the purpose of this study was to determine whether there was a difference in depression levels and rate of complications based on gender early after AMI.

\subsection{Research Hypotheses}

1. Female patients will have higher depression scores than male patients. 
2. Female patients will have a higher complication rate than male patients.

3. Depression scores will be an independent predictor for complications (for men and women) after controlling for sociodemographic and clinical variables.

\section{MATERIAL AND METHODS}

\subsection{Research design, Sample, and Setting}

To meet the objective of this study, a prospective comparative design was used. The study was conducted at 3 private hospitals in Amman, Jordan. The inclusion criteria were (1) a confirmed diagnosis of AMI by elevated cardiac enzymes, standard electrocardiogram (ECG) changes, and/or chest pain; (2) 18 years and older; (3) no chest pain and hemodynamic stable at the time of interview; (4) no cognitive impairment affecting the ability to answer questionnaires; and (5) no previously diagnosed psychiatric disorder. A power analysis based on Cohen power table was conducted [39] to ensure that the sample size was sufficient to detect statistical significance based on the following criteria; a) medium effect size, b) a power of $0.80, c)$ a type I error of 0.05 , and d) the statistical tests were mean difference for hypotheses 1 and 2, and regression with 7 independent variables for hypothesis 3 . Based on these assumptions, 64 participants were needed for hypotheses 1 and 2, whereas 106 participants were needed for hypothesis 3 . Therefore, it was determined that the sample size of 230 was adequate.

\subsection{Ethical Considerations}

This study was reviewed and approved by the institutional review board (IRB) committee at the Applied Science Private University, Amman, Jordan (faculty 005). Thereafter, the principal investigator presented the study proposal and submitted the IRB approval letter to the medical and nursing directors of the selected hospitals. These institutions acknowledged the IRB approval from the Applied Science Private University. Therefore, permissions to carry out the study within these hospitals were issued to the principal investigators by the medical directors.

\subsection{Procedure}

Experienced cardiovascular research assistants met with the participants and explained the study objectives. Participants were assured that participation was voluntary and they could withdraw from the study at any time. Then, they signed an informed consent if they agreed to participate. Research assistants collected data from each participant within 72 hours (mean [SD], 38 hours [19]) of admission to the hospital. The following were completed during the interview; sociodemographic and clinical questionnaire and the Depression Subscale of the Hospital Anxiety and Depression Scale (HADS). In addition, clinical data were abstracted from the participants' medical records after discharge.

\subsection{Measurement of Variables}

\subsubsection{Sociodemographic and Clinical Characteristics}

Data were obtained by research assistants either by face to face interview or by reviewing medical records. Sociodemographic and clinical data collected were: age, gender, marital status, admission vital signs, smoking history, medications history, and medical history of (hypertension, diabetes, previous myocardial infarction, and previous angina), surgical history/intervention of (coronary artery bypass graft, percutaneous transluminal intervention, and stent use). In addition, we measured the Intensive Care Unit (ICU) and hospital Lengths Of Stay (LOSs), Left Ventricular Ejection Fraction (LVEF) from the medical records.

\subsubsection{Depression}

The depression subscale of the HADS was used to measure depression in this study. This subscale is translated into Arabic, short, easy to use and interpret, valid, and reliable [40 - 44]. The Cronbach's for the Arabic version of this subscale was 87 . The sensitivity and specificity were at $79 \%$ and $87 \%$, respectively $[41,43,44]$. The HADS consists of 7 -items in which the participants rated each item on a scale of 0 to 3 , with 3 indicating higher symptom frequency and severity. The items were summed to a total score that ranged from 0 to 21 , with higher scores indicating higher levels of depressive symptoms. The scores were categorized as follows: 0 to 7 , normal; 8 to 10 , mild; 11 to 14 , moderate; and 15 to 21 , severe depression [40]. 


\subsubsection{In-hospital Complications}

Complications were defined as in previous studies [3, 7, 17, 18, 45] as the occurrence of any of the following during hospitalization: (a) reinfarction evidenced by elevated cardiac enzymes and standard ECG changes; (b) supraventricular tachyarrhythmia with hemodynamic instability, (c) acute recurrent ischemia evidenced by new onset of chest pain, with ECG changes or hemodynamic instability; (d) sustained ventricular tachycardia ( $\geq 30$ seconds) or any ventricular tachycardia requiring cardioversion and/or pharmacological intervention; (e) ventricular fibrillation; (f) cardiogenic shock; (g) acute pulmonary edema; or (h) in-hospital death.

\subsection{Data Analysis}

Data were analyzed using SPSS software version 21.0 (SPSS Inc, Chicago, Illinois). $P$-Value less than .05 was set a priori. Sociodemographic and clinical characteristics of the sample based on gender were described using frequencies and percentages or mean (SD). Independent-sample t-test was used to test the first 2 hypotheses of the study. Correlations between depression scores for both genders and the total number of complications, ICU LOS, and hospital LOS were examined using the Pearson $r$ correlation coefficient. Predictors of complication for both genders (hypothesis 3) were tested using logistic regression.

\section{RESULTS}

230 patients participated in this study, 150 men and 80 women. Table 1 presents the sociodemographic and clinical characteristics of the sample by gender. Three-quarters of the sample was hypertensive, more than half of the sample had previous AMI, and the majority had a history of angina. Male patients more often had diabetes $\left(X^{2}=8.01, \mathrm{P}<.01\right)$, had a higher prevalence of previous angina $\left(X^{2}=11.02, \mathrm{P}<.01\right)$, and had coronary artery bypass graft surgery more commonly $\left(X^{2}=8.87, \mathrm{P}<.01\right)$ than female patients did. However, female patients have significantly lower levels of LVEF compared to male patients.

Table 1. Sociodemographic and clinical characteristics of the sample by gender.

\begin{tabular}{|c|c|c|c|}
\hline Variable & Total sample (n=230) & Males (n=150) & Females $(\mathbf{n}=\mathbf{8 0})$ \\
\hline Age & $66.6 \pm 11.2$ & $65.5 \pm 11.1$ & $67.5 \pm 10.6$ \\
\hline LVEF & $30.8 \pm 6.0$ & $32.5 \pm 8.2$ & $29.8 \pm 4.0^{*}$ \\
\hline History of hypertension & $173(75.2)$ & $118(78.7)$ & $55(68.8)$ \\
\hline History of diabetes & $89(38.7)$ & $68(42.3)$ & $21(26.3)^{* *}$ \\
\hline History of previous AMI & $138(60.0)$ & $93(62.0)$ & $45(56.3)$ \\
\hline History of previous angina & $190(82.6)$ & $133(88.7)$ & $57(71.3)^{* *}$ \\
\hline History of previous CABG & $134(58.3)$ & $98(65.3)$ & $36(45.0)^{* *}$ \\
\hline History of stent use & $101(43.9)$ & $71(47.3)$ & $30(37.5)$ \\
\hline Had any complication during hospitalization & $86(37.4)$ & $54(36.0)$ & $32(40.0)$ \\
\hline Smoking & $71(30.9)$ & $34(22.7)$ & $37(46.3)$ \\
Never smoked & $57(24.8)$ & $46(30.7)$ & $11(13.8)$ \\
Forrent smoker & $102(44.3)$ & $70(76.7)$ & $32(40.0)$ \\
\hline
\end{tabular}

LVEF: left ventricular ejection fraction, AMI: Acute myocardial infarction, CABG: coronary artery bypass graft, *significant at $\mathrm{p}<.05, * *$ significant at $\mathrm{p}<.01$

Eighty-six participants (37.4\%), 54 men and 32 women, developed 1 or more complications during hospitalization Table 2. Female patients were more depressed and developed complications more than male patients did Table 3. Female patients were moderately depressed based on the operational definition of HADS with a mean (SD) of 14.4 (3.5). Male patients were mildly depressed based on a mean (SD) for the HADS of 8.3 (2.6).

Table 2. Specific complications developed and their percentages.

\begin{tabular}{|c|c|}
\hline Complication Developed & *Number of Patients (\%) \\
\hline Acute recurrent ischemia & $52(22.6)$ \\
\hline Sustained ventricular tachycardia & $12(5.2)$ \\
\hline Pulmonary edema & $7(3.0)$ \\
\hline Re-infarction & $7(3.0)$ \\
\hline Cardiogenic shock & $6(2.6)$ \\
\hline
\end{tabular}




\begin{tabular}{|c|c|}
\hline Table 2) contd..... & *Number of Patients (\%) \\
\hline In-hospital death. & $6(2.6)$ \\
\hline Ventricular fibrillation & $5(2.2)$ \\
\hline *More than one patient developed more than one complication \\
\hline
\end{tabular}

Table 3. Comparison of depression level and complication based on gender.

\begin{tabular}{|c|c|c|c|c|}
\hline Item & Gender & Means & SD & P Value \\
\hline Depression level (HADS; depression subscale scores) & $\begin{array}{c}\text { Female } \\
\text { Male }\end{array}$ & $\begin{array}{c}14.4 \\
8.3\end{array}$ & $\begin{array}{l}3.5 \\
2.6\end{array}$ & $<.01$ \\
\hline Complications & $\begin{array}{c}\text { Female } \\
\text { Male }\end{array}$ & $\begin{array}{l}1.9 \\
0.8\end{array}$ & $\begin{array}{l}0.9 \\
0.5\end{array}$ & $<.05$ \\
\hline
\end{tabular}

HADS: Hospital anxiety and Depression Scale.

The correlation between depression scores for males and females and the total number of complications, ICU LOS, and hospital LOS are presented in Table 4. The only significant correlation was between the number of complications with the depression scores for female patients $(\mathrm{r}=0.21, \mathrm{P}<.05)$.

Table 4. Correlation between depression scores based on gender with complications and LOS.

\begin{tabular}{|c|c|c|c|}
\hline Variable & Complication & ICU LOS & Hospital LOS \\
\hline depression Scores/male patients & $0.02(\mathrm{NS})$ & 0.03 (NS) & 0.06 (NS) \\
\hline depression Scores/ female patients & $0.21^{*}$ & 0.02 (NS) & 0.07 (NS) \\
\hline
\end{tabular}

LOS: Length of stay, ICU: Intensive Care Unit, *significant at $\mathrm{P}<.05$, NS: Not significant.

Two separate logistic regression equations were used to predict the occurrence of complications using the same predictors entered for male and female patients. History of hypertension and depression scores were independent predictors of complication for male patients Table 5, whereas depression scores were the only predictor for complication of female patients Table 6. Depressive symptoms increased the risk for development of complication for men by $33 \%$ and for women by $40 \%$.

Table 5. Predictors of complication for male patients.

\begin{tabular}{|c|c|c|c|c|c|}
\hline Predictor & OR & $95 \%$ confidence interval & B & Wald & P-value \\
\hline Age & 1.02 & $0.99-1.08$ & 0.03 & 3.4 & 0.07 \\
\hline Previous AMI & 0.74 & $0.35-1.55$ & -0.31 & 0.66 & 0.42 \\
\hline Diabetes & 0.90 & $0.43-1.90$ & -0.11 & 0.08 & 0.78 \\
\hline Hypertension & 2.53 & $1.07-6.43$ & 0.93 & 3.77 & $<0.05$ \\
\hline Previous CABG & 1.89 & $0.88-4.10$ & 0.64 & 2.65 & 0.10 \\
\hline Depression scores & 1.33 & $1.21-2.24$ & 0.19 & 28.15 & $<0.001$ \\
\hline
\end{tabular}

OR: Odds ratio, AMI: Acute Myocardial Infarction, CABG: Coronary Artery Bypass Graft Surgery

Table 6. Predictors of complication for female patients.

\begin{tabular}{|c|c|c|c|c|c|}
\hline Predictor & OR & 95\% confidence interval & B & Wald & P- value \\
\hline Age & 1.00 & $0.96-1.05$ & 0.001 & 0.002 \\
\hline Previous AMI & 0.48 & $0.18-1.25$ & -0.74 & 2.27 \\
\hline Diabetes & 0.75 & $0.26-2.13$ & -0.29 & 0.29 & 0.13 \\
\hline Hypertension & 1.45 & $0.52-4.08$ & 0.57 & 0.50 & 0.48 \\
\hline Previous CABG & 0.94 & $0.36-2.44$ & -0.06 & 0.02 & 0.90 \\
\hline Depression scores & 1.40 & $1.09-1.88$ & 0.61 & 39.32 & $<\mathbf{0 . 0 0 1}$ \\
\hline
\end{tabular}

OR: Odds ratio, AMI: Acute Myocardial Infarction, CABG: Coronary Artery Bypass Graft Surgery

\section{DISCUSSION}

This was the first study specifically designed to check the differences in depression levels and complication rate after AMI between males and females in a developing country. The major findings of this study were that female patients had higher levels of depressive symptoms and complications compared to male patients. In addition, depressive symptoms were independent predictor of these complications for male and females at the same time. 
The results of this study showed that females have more depressive symptoms than males. This result is consistent with previous studies $[15,20,25,26,46-48]$ conducted on the same topic. Different explanations were proposed for this result. First: Previous research showed that poor LVEF was associated with depression in patients with coronary artery disease [20, 49], heart failure [20, 50], and post AMI [20, 51]. Moreover, low levels of LVEF were important predictors for poor quality of life in all domains for heart failure patients following AMI, including mental and physical components $[52,53]$. In this study, female patients had significantly lower LVEF compared to males which might explain why they had higher levels of depressive symptoms. Second: Women may more often have preexisting depression prior to the AMI event compared to men, which might exaggerates the depressive symptoms after AMI [54]. Third: Recently, research starts to focus on the relationship between fetal exposure and the increased risk for depression in females, which still needs further studies [55]. Fourth: Previous research found that females had higher levels of fatigue after AMI event, and fatigue was positively correlated with depressive symptoms. Further research explaining why females have more depression after AMI is still warranted.

The results of this study also showed that depressive symptoms were independent predictors of in-hospital complication for both males and females. These results are consistent with previous studies about the relationship between depression and in-hospital complications [7, 15, 56, 57]. The most recent study [7] on 175 post AMI patients demonstrated that depressive symptoms were associated with increased risk of in-hospital complications including acute recurrent ischemia, re-infarction, sustained ventricular tachycardia, ventricular fibrillation; or in-hospital death. Kerrat et al (2010) [15] measured depression by BDI in 906 patients with AMI and unstable angina. Among them, 492 (58.4\%) developed complications including ischemia, sudden cardiac arrest, arrhythmia, re-infarction, major bleed, and had a temporary transvenous pacemaker. The study showed that depressive symptoms were significantly associated with these complications. Moreover, ischemia was the most prevalent complication as in the current study.

Huffman et al (2008) [11] showed that clinical depression measured by interview was associated with cardiac complications in 129 AMI patients. These complications included ventricular arrhythmias, heart failure and recurrent AMI. These results are consistent with the results by dickens et al. [57] who found that clinical depression was an independent predictor of the occurrence of heart failure after AMI.

Contrary, Cherrington et al [58] checked the association between depressive symptoms and anxiety with in-hospital complications after AMI. They found that neither depressive symptoms nor anxiety was associated with in-hospital complications. A possible explanation might be the small sample size of the study; there were only 49 patients enrolled in this study.

Most of the previous studies about the difference between female and male patients focused on long term complications and mortality. Limited number of studies [3, 15, 23, 47] checked the differences between female and male patients in the development of in-hospital complications after AMI. In the current study, female patients developed more complications than male patients. This result is consistent with different previous studies about inhospital complication.

In this study and Grewal et al study [15] described previously, female patients had higher levels of depressive symptoms than male patients. Since depression is strongly associated with complication, it is no wonder that female patients developed more complications than male patients. Moreover, female patients in the current study had lower levels of LVEF compared to male patients giving further support for these results. It has also been shown in another study about anxiety and complications after AMI in a developing country that female patients developed more complications compared to male patients [3]. Female patients were severely anxious, while male patients were mildly anxious which explain the results.

In a study of 11,896 Chinese patients recruited from 162 Chinese hospitals [47], the overall in-hospital mortality rate was higher in women compared to men, even after adjustment for sociodemographic and clinical characteristics. The same results were obtained from an Italian study [23] which enrolled 89,562 patients with a confirmed diagnosis of ST-elevation MI. In-hospital mortality was higher among female patients compared to male patients. However, there was an age-gender interaction with female gender being a significant predictor of increased mortality in patients aged $\geq 75$ years.

Contrary, only one study [59] reported that male patients had more complications, namely (severe arrhythmias), than female patients. It is worthy to note that the sample of this study consisted of (9737) patients suffering an episode of chest pain aged between 25-74 years who were admitted to the CCU. Signs and symptoms of AMI were presented in 2500 male patients and 979 female patients. Male patients were taking antiarrhythmias more than female patients which 
might explain the results of the study. Antiarrhythmias medications usually have the development of new arrhythmias as one of their side effects.

\section{CONCLUSION AND IMPLICATION}

This was the first study to check the effect of depressive symptoms and gender differences on in-hospital complication after AMI in a developing country. The results showed that depressive symptoms increased in-hospital complications after AMI. Female patients have more depressive symptoms than male patients did, which made them more susceptible to these complications. These results are approximately the same with the results obtained from developed countries indicating that depression is a global problem after AMI, especially for women. Previous studies demonstrated that effective treatment of depression reduced mortality in depressed post AMI patients. However, depression in this population cannot be treated unless it is firstly identified. Therefore, it is highly recommended to include depression assessment in AMI treatment protocols. Future studies to determine the physiological and psychological mechanisms to explain this difference between female and male patients are still needed.

\section{ETHICS APPROVAL AND CONSENT TO PARTICIPATE}

This study was reviewed and approved by the institutional review board (IRB) committee at the Applied SciencePrivate University, Amman, Jordan (faculty 005).

\section{HUMAN AND ANIMAL RIGHTS}

No Animals/Humans were used for studies that are base of this research.

\section{CONSENT FOR PUBLICATION}

Informed cosent have been obtained.

\section{CONFLICT OF INTEREST}

The authors declare no conflict of interest, financial or otherwise.

\section{ACKNOWLEDGEMENTS}

The authors are grateful to Applied Science Private University, Amman, Jordan, for the partial financial support granted to this research project, and the financial support granted to cover the publication fees of this research article.

\section{REFERENCES}

[1] Benjamin EJ, Virani SS, Callaway CW, et al. Heart disease and stroke statistics-2018 update: A report from the american heart association. Circulation 2018; 137(12): e67-e492. [http://dx.doi.org/10.1161/CIR.0000000000000558] [PMID: 29386200]

[2] WHO. Jordan: WHO statistical profile : Country statistics and global health estimates by WHO and UN partner Available from 2015. http://www.who.int/countries/jor/en/ cited 2015 10/5/2016

[3] AbuRuz ME, Masa'Deh R. Gender differences in anxiety and complications early after acute myocardial infarction. J Cardiovasc Nurs 2017; 32(6): 538-43. [http://dx.doi.org/10.1097/JCN.0000000000000375] [PMID: 28591003]

[4] Townsend N, Nichols M, Scarborough P, Rayner M. Cardiovascular disease in Europe 2015: Epidemiological update. Eur Heart J 2015; 36(40): 2673-4.

[http://dx.doi.org/10.1093/eurheartj/ehv428] [PMID: 26788564]

[5] Gehani AA, Al-Hinai AT, Zubaid M, et al. Association of risk factors with acute myocardial infarction in Middle Eastern countries: The INTERHEART Middle East study. Eur J Prev Cardiol 2014; 21(4): 400-10. [http://dx.doi.org/10.1177/2047487312465525] [PMID: 23125402]

[6] Meijer A, Conradi HJ, Bos EH, Thombs BD, van Melle JP, de Jonge P. Prognostic association of depression following myocardial infarction with mortality and cardiovascular events: a meta-analysis of 25 years of research. Gen Hosp Psychiatry 2011; 33(3): 203-16. [http://dx.doi.org/10.1016/j.genhosppsych.2011.02.007] [PMID: 21601716]

[7] AbuRuz ME, Alaloul F, Al-Dweik G. Depressive symptoms are associated with in-hospital complications following acute myocardial infarction. Appl Nurs Res 2018; 39: 65-70. [http://dx.doi.org/10.1016/j.apnr.2017.11.001] [PMID: 29422179]

[8] Thombs BD, Bass EB, Ford DE, et al. Prevalence of depression in survivors of acute myocardial infarction. J Gen Intern Med 2006; 21(1): $30-8$. 
[http://dx.doi.org/10.1111/j.1525-1497.2005.00269.x] [PMID: 16423120]

[9] Barth J, Schumacher M, Herrmann-Lingen C. Depression as a risk factor for mortality in patients with coronary heart disease: A metaanalysis. Psychosom Med 2004; 66(6): 802-13.

[http://dx.doi.org/10.1097/01.psy.0000146332.53619.b2] [PMID: 15564343]

[10] Banankhah SK, Friedmann E, Thomas S. Effective treatment of depression improves post-myocardial infarction survival. World J Cardiol 2015; 7(4): 215-23.

[http://dx.doi.org/10.4330/wjc.v7.i4.215] [PMID: 25914790]

[11] Huffman JC, Smith FA, Blais MA, Taylor AM, Januzzi JL, Fricchione GL. Pre-existing major depression predicts in-hospital cardiac complications after acute myocardial infarction. Psychosomatics 2008; 49(4): 309-16. [http://dx.doi.org/10.1176/appi.psy.49.4.309] [PMID: 18621936]

[12] Frasure-Smith N, Lespérance F, Talajic M. Depression following myocardial infarction. Impact on 6-month survival. JAMA 1993; 270(15): $1819-25$.

[http://dx.doi.org/10.1001/jama.1993.03510150053029] [PMID: 8411525]

[13] Barefoot JC, Brummett BH, Helms MJ, Mark DB, Siegler IC, Williams RB. Depressive symptoms and survival of patients with coronary artery disease. Psychosom Med 2000; 62(6): 790-5. [http://dx.doi.org/10.1097/00006842-200011000-00008] [PMID: 11138998]

[14] Thornton LA. Depression in post-acute myocardial infarction patients. J Am Acad Nurse Pract 2001; $13(8)$ : $364-7$. [http://dx.doi.org/10.1111/j.1745-7599.2001.tb00051.x] [PMID: 11930571]

[15] Grewal K, Stewart DE, Abbey SE, Leung YW, Irvine J, Grace SL. Timing of depressive symptom onset and in-hospital complications among acute coronary syndrome inpatients. Psychosomatics 2010; 51(4): 283-8. [http://dx.doi.org/10.1016/S0033-3182(10)70698-8] [PMID: 20587755]

[16] Abed MA, Frazier S, Hall LA, Moser DK. Anxiolytic medication use is not associated with anxiety level and does not reduce complications after acute myocardial infarction. J Clin Nurs 2013; 22(11-12): 1559-68. [http://dx.doi.org/10.1111/jocn.12064] [PMID: 23311616]

[17] Abu Ruz ME, Lennie TA, Moser DK. Effects of $\beta$-blockers and anxiety on complication rates after acute myocardial infarction. Am J Crit Care $2011 ; 20(1): 67-73$.

[http://dx.doi.org/10.4037/ajcc2010216] [PMID: 20107234]

[18] Mohannad Eid AbuRuz AS, Demeh Waddah. Anxiolytic medication use does not have a protective effect against complications after acute myocardial infraction. Life Sci J 2013; 10(4): 1333-7.

[19] Moser DK, Dracup K. Is anxiety early after myocardial infarction associated with subsequent ischemic and arrhythmic events? Psychosom Med 1996; 58(5): 395-401. [http://dx.doi.org/10.1097/00006842-199609000-00001] [PMID: 8902890]

[20] Doyle F, McGee H, Conroy R, et al. Systematic review and individual patient data meta-analysis of sex differences in depression and prognosis in persons with myocardial infarction: A MINDMAPS study. Psychosom Med 2015; 77(4): 419-28. [http://dx.doi.org/10.1097/PSY.0000000000000174] [PMID: 25886829]

[21] Wittchen HU, Jacobi F, Rehm J, et al. The size and burden of mental disorders and other disorders of the brain in Europe 2010. Eur Neuropsychopharmacol 2011; 21(9): 655-79.

[http://dx.doi.org/10.1016/j.euroneuro.2011.07.018] [PMID: 21896369]

[22] Van de Velde S, Bracke P, Levecque K. Gender differences in depression in 23 European countries. Cross-national variation in the gender gap in depression. Soc Sci Med 2010; 71(2): 305-13. [http://dx.doi.org/10.1016/j.socscimed.2010.03.035] [PMID: 20483518]

[23] Corrada E, Ferrante G, Mazzali C, et al. Eleven-year trends in gender differences of treatments and mortality in ST-elevation acute myocardial infarction in northern Italy, 2000 to 2010. Am J Cardiol 2014; 114(3): 336-41. [http://dx.doi.org/10.1016/j.amjcard.2014.05.007] [PMID: 24925728]

[24] Smolderen KG, Strait KM, Dreyer RP, et al. Depressive symptoms in younger women and men with acute myocardial infarction: Insights from the virgo study. J Am Heart Assoc 2015; 4(4): e001424. [http://dx.doi.org/10.1161/JAHA.114.001424] [PMID: 25836055]

[25] Frazier L, Yu E, Sanner J, et al. Gender differences in self-reported symptoms of depression among patients with acute coronary syndrome. Nurs Res Pract 2012; 2012: 109251. [http://dx.doi.org/10.1155/2012/109251] [PMID: 22567222]

[26] Dreyer RP, Smolderen KG, Strait KM, et al. Gender differences in preevent health status of young patients with acute myocardial infarction: A virgo study analysis. Eur Heart J Acute Cardiovasc Care 2016; 5(1): 43-54. [http://dx.doi.org/10.1177/2048872615568967] [PMID: 25681487]

[27] Dreyer RP, Wang Y, Strait KM, et al. Gender differences in the trajectory of recovery in health status among young patients with acute myocardial infarction: Results from the variation in recovery: Role of gender on outcomes of young AMI patients (VIRGO) study. Circulation 2015; 131(22): 1971-80.

[http://dx.doi.org/10.1161/CIRCULATIONAHA.114.014503] [PMID: 25862743] 
[28] Möller-Leimkühler AM. Women with coronary artery disease and depression: A neglected risk group. World J Biol Psychiatry 2008; 9(2): 92-101. [http://dx.doi.org/10.1080/15622970701275281] [PMID: 17853281]

[29] Weissman MM, Olfson M. Depression in women: Implications for health care research. Science 1995; 269(5225): 799-801. [http://dx.doi.org/10.1126/science.7638596] [PMID: 7638596]

[30] Bland RC, Orn H, Newman SC. Lifetime prevalence of psychiatric disorders in Edmonton. Acta Psychiatr Scand Suppl 1988; 338: 24-32. [http://dx.doi.org/10.1111/j.1600-0447.1988.tb08544.x] [PMID: 3165592]

[31] Wittchen HU, Essau CA, von Zerssen D, Krieg JC, Zaudig M. Lifetime and six-month prevalence of mental disorders in the Munich FollowUp Study. Eur Arch Psychiatry Clin Neurosci 1992; 241(4): 247-58. [http://dx.doi.org/10.1007/BF02190261] [PMID: 1576182]

[32] Preisig M, Merikangas KR, Angst J. Clinical significance and comorbidity of subthreshold depression and anxiety in the community. Acta Psychiatr Scand 2001; 104(2): 96-103. [http://dx.doi.org/10.1034/j.1600-0447.2001.00284.x] [PMID: 11473502]

[33] Parashar S, Rumsfeld JS, Reid KJ, et al. Impact of depression on sex differences in outcome after myocardial infarction. Circ Cardiovasc Qual Outcomes 2009; 2(1): 33-40.

[http://dx.doi.org/10.1161/CIRCOUTCOMES.108.818500] [PMID: 20031810]

[34] Amy Wenze RAS, Aaron T. Becka. Are there any gender differences in frequency of self-reported somatic symptoms of depression? J Affect Disord 2005; 89(1-3): 171-81.

[35] Silverstein B. Gender differences in the prevalence of somatic versus pure depression: A replication. Am J Psychiatry 2002; 159(6): 1051-2. [http://dx.doi.org/10.1176/appi.ajp.159.6.1051] [PMID: 12042198]

[36] Lichtman JH, Froelicher ES, Blumenthal JA, et al. Depression as a risk factor for poor prognosis among patients with acute coronary syndrome: Systematic review and recommendations: A scientific statement from the american heart association. Circulation 2014; 129(12): 1350-69. [http://dx.doi.org/10.1161/CIR.0000000000000019] [PMID: 24566200]

[37] Radovanovic D, Erne P, Urban P, Bertel O, Rickli H, Gaspoz JM. Gender differences in management and outcomes in patients with acute coronary syndromes: Results on 20,290 patients from the AMIS plus registry. Heart 2007; 93(11): 1369-75. [http://dx.doi.org/10.1136/hrt.2006.106781] [PMID: 17933995]

[38] Jneid H, Fonarow GC, Cannon CP, et al. Sex differences in medical care and early death after acute myocardial infarction. Circulation 2008; 118(25): 2803-10. [http://dx.doi.org/10.1161/CIRCULATIONAHA.108.789800] [PMID: 19064680]

[39] Cohen J. A power primer. Psychol Bull 1992; 112(1): 155-9. [http://dx.doi.org/10.1037/0033-2909.112.1.155] [PMID: 19565683]

[40] Bjelland I, Dahl AA, Haug TT, Neckelmann D. The validity of the hospital anxiety and depression scale. An updated literature review. J Psychosom Res 2002; 52(2): 69-77. [http://dx.doi.org/10.1016/S0022-3999(01)00296-3] [PMID: 11832252]

[41] el-Rufaie OE, Albar AA, Al-Dabal BK. Identifying anxiety and depressive disorders among primary care patients: A pilot study. Acta Psychiatr Scand 1988; 77(3): 280-2.

[http://dx.doi.org/10.1111/j.1600-0447.1988.tb05121.x] [PMID: 3394530]

[42] el-Rufaie OE, Absood G. Validity study of the hospital anxiety and depression scale among a group of saudi patients. Br J Psychiatry 1987; 151: $687-8$. [http://dx.doi.org/10.1192/bjp.151.5.687] [PMID: 3446314]

[43] el-Rufaie OE, Absood GH. Retesting the validity of the arabic version of the hospital Anxiety and Depression (HAD) scale in primary health care. Soc Psychiatry Psychiatr Epidemiol 1995; 30(1): 26-31. [http://dx.doi.org/10.1007/BF00784431] [PMID: 7892615]

[44] Malasi TH, Mirza IA, el-Islam MF. Validation of the hospital anxiety and depression scale in arab patients. Acta Psychiatr Scand 1991; 84(4): 323-6.

[http://dx.doi.org/10.1111/j.1600-0447.1991.tb03153.x] [PMID: 1746281]

[45] McKinley S, Fien M, Riegel B, et al. Complications after acute coronary syndrome are reduced by perceived control of cardiac illness. J Adv Nurs 2012; 68(10): 2320-30. [http://dx.doi.org/10.1111/j.1365-2648.2011.05933.x] [PMID: 22235775]

[46] Doering LV, McKinley S, Riegel B, et al. Gender-specific characteristics of individuals with depressive symptoms and coronary heart disease. Heart Lung 2011; 40(3): e4-e14. [http://dx.doi.org/10.1016/j.hrtlng.2010.04.002] [PMID: 20561880]

[47] Nedkoff L, Atkins E, Knuiman M, Sanfilippo FM, Rankin J, Hung J. Age-specific gender differences in long-term recurrence and mortality following incident myocardial infarction: A population-based study. Heart Lung Circ 2015; 24(5): 442-9. [http://dx.doi.org/10.1016/j.hlc.2014.11.022] [PMID: 25618449] 
[48] Bjerkeset O, Nordahl HM, Mykletun A, Holmen J, Dahl AA. Anxiety and depression following myocardial infarction: Gender differences in a 5-year prospective study. J Psychosom Res 2005; 58(2): 153-61. [http://dx.doi.org/10.1016/j.jpsychores.2004.07.011] [PMID: 15820843]

[49] Lehto S, Koukkunen H, Hintikka J, Viinamäki H, Laakso M, Pyörälä K. Depression after coronary heart disease events. Scand Cardiovasc J 2000; 34(6): 580-3. [http://dx.doi.org/10.1080/140174300750064512] [PMID: 11214011]

[50] Freedland KE, Rich MW, Skala JA, Carney RM, Dávila-Román VG, Jaffe AS. Prevalence of depression in hospitalized patients with congestive heart failure. Psychosom Med 2003; 65(1): 119-28. [http://dx.doi.org/10.1097/01.PSY.0000038938.67401.85] [PMID: 12554823]

[51] van Melle JP, de Jonge P, Ormel J, et al. Relationship between left ventricular dysfunction and depression following myocardial infarction: Data from the MIND-IT. Eur Heart J 2005; 26(24): 2650-6. [http://dx.doi.org/10.1093/eurheartj/ehi480] [PMID: 16143708]

[52] Alaloul F, AbuRuz ME, Moser DK, Hall LA, Al-Sadi A. Factors associated with quality of life in arab patients with heart failure. Scand J Caring Sci 2017; 31(1): 104-11. [http://dx.doi.org/10.1111/scs.12324] [PMID: 27279004]

[53] AbuRuz ME, Alaloul F, Saifan A, Masa'deh R, Abusalem S. Quality of life for saudi patients with heart failure: A cross-sectional correlational study. Glob J Health Sci 2015; 8(3): 49-58. [http://dx.doi.org/10.5539/gjhs.v8n3p49] [PMID: 26493415]

[54] Kendler KS, Gardner CO, Fiske A, Gatz M. Major depression and coronary artery disease in the swedish twin registry: Phenotypic, genetic, and environmental sources of comorbidity. Arch Gen Psychiatry 2009; 66(8): 857-63. [http://dx.doi.org/10.1001/archgenpsychiatry.2009.94] [PMID: 19652125]

[55] Goldstein JM, Cherkerzian S, Buka SL, et al. Sex-specific impact of maternal-fetal risk factors on depression and cardiovascular risk 40 years later. J Dev Orig Health Dis 2011; 2(6): 353-64. [http://dx.doi.org/10.1017/S2040174411000651] [PMID: 23378891]

[56] Huffman JC, Doughty CT, Januzzi JL, Pirl WF, Smith FA, Fricchione GL. Screening for major depression in post-myocardial infarction patients: Operating characteristics of the Beck Depression Inventory-II. Int J Psychiatry Med 2010; 40(2): 187-97. [http://dx.doi.org/10.2190/PM.40.2.e] [PMID: 20848875]

[57] Dickens C, McGowan L, Percival C, et al. Association between depressive episode before first myocardial infarction and worse cardiac failure following infarction. Psychosomatics 2005; 46(6): 523-8. [http://dx.doi.org/10.1176/appi.psy.46.6.523] [PMID: 16288131]

[58] Cherrington CC, Moser DK, Lennie TA, Kennedy CW. Illness representation after acute myocardial infarction: Impact on in-hospital recovery. Am J Crit Care 2004; 13(2): 136-45.

[PMID: 15043241]

[59] Gregor RD, Bata IR, Eastwood BJ, et al. Gender differences in the presentation, treatment, and short-term mortality of acute chest pain. Clin Invest Med 1994; 17(6): 551-62.

[PMID: 7895419]

(C) 2018 AbuRuz and Al-Dweik.

This is an open access article distributed under the terms of the Creative Commons Attribution 4.0 International Public License (CC-BY 4.0), a copy of which is available at: https://creativecommons.org/licenses/by/4.0/legalcode. This license permits unrestricted use, distribution, and reproduction in any medium, provided the original author and source are credited. 